Research Article

\title{
Evaluation of the efficacy of Brahmi ghrita in scopolamine induced amnesia in rats using Cook's pole apparatus
}

\author{
Renuka Munshi ${ }^{1}$, Supriya Bhalerao ${ }^{1}$, Tanuja Nesari ${ }^{2}$
}

\begin{abstract}
${ }^{1}$ Department of Clinical
Pharmacology, TN Medical

College and BYL Nair

Charitable Hospital, Mumbai Sansthan, New Delhi, India

Received: 03 March 2016

Revised: 12 March 2016

Accepted: 08 April 2016

\section{*Correspondence to: \\ Dr. Renuka Munshi, \\ Email: renuka.munshi}

@gmail.com
\end{abstract}

Central, Mumbai 400008, India

${ }^{2}$ Department of Dravyaguna, Ch. Brahm Prakash Ayurved Charak

Copyright: (c) the author(s), publisher and licensee Medip Academy. This is an openaccess article distributed under the terms of the Creative Commons Attribution NonCommercial License, which permits unrestricted noncommercial use, distribution, and reproduction in any medium, provided the original work is properly cited.

\begin{abstract}
Background: Memory is the process, in which information is encoded, stored, and retrieved. Age, overstress, emotions can result in an impairment of memory. This may also be a symptom of various neuro-degenerative disorders. The objective of this study was carried out to evaluate the effect of pre-treatment of Brahmi ghrita on scopolamine-induced amnesia in rats using cook's pole apparatus.

Methods: Following Institutional Animal Ethics Committee permission, the study was conducted in Wistar rats (150-225 gms) of either sex. Brahmi ghrita $(450 \mathrm{mg} / \mathrm{kg}$ ) was administered for 15 days as a pre-treatment. Scopolamine (30 $\mathrm{mg} / \mathrm{kg}$ bw, i.p.) was injected on day 16 and the effect of Brahmi ghrita was studied using Cook's pole apparatus. Parameters assessed were number of conditional avoidance responses (CAR), unconditional responses and no response out of 30 sessions, serum MDA, and brain MDA and brain acetylcholine esterase (AChE) activity. Piracetam, a known nootropic was used as a positive control.

Results: Scopolamine as expected showed a decrease in CAR as compared to normal control after 4 hours and, after 24 hours. Brahmi ghrita significantly improved the conditioned avoidance response (CAR), at both 4 and 24 hours, demonstrating its memory protective effect. Piracetam also showed decrease in CAR. Brahmi ghrita improved the serum and brain MDA levels significantly as compared to the Scopolamine. However Piracetam further augmented the oxidative stress induced by scopolamine. Brahmi ghrita also decreased the AChE activity (increased by scopolamine administration) emphasizing its memory protective effect. Piracetam was seen to increase the AChE activity.

Conclusions: Thus, the study demonstrated the efficacy of Brahmi ghrita as an anti-amnestic, anti-oxidant and AChE inhibitor.
\end{abstract}

Keywords: Brahmi ghrita, scopolamine-induced amnesia, Cook's pole apparatus, CAR, MDA, AChE

\section{INTRODUCTION}

Memory is the process, in which information is encoded, stored, and retrieved. ${ }^{1}$ Age, overstress, emotions can result in an impairment of memory. This may also be a symptom of various neuro-degenerative disorders. Cure of cognitive disorders such as amnesia, attention deficit and Alzheimer's disease is still a nightmare in the field of medicine. Nootropic agents such as Piracetam, Aniracetam and choline esterase inhibitors like Donepezil are used to improve memory, mood and behaviour, but the associated side effects has limited their long term use. $^{2}$ Against this background, Ayurveda describes many formulations to improve memory and have neuroprotective effects.

Bramhi ghrita, is one such a formulation recommended in Ayurveda for treating memory loss associated with convulsion. ${ }^{3}$ This formulation contains four plants viz. Bacopa monneri (Bramhi), Convolvulus pluricaulis 
(Shankhpushpi), Acorus calamus (Vacha) and Alpinia galangal (Kushtha) and is processed in ghrita (ghee prepared from cow's milk). ${ }^{4}$ All these plants are as Medhya (intellect promoting). The CNS activity of this formulation and its effect on learning and memory paradigm in normal animals have been reported by Achilya GS et al. ${ }^{3}$ The individual plant drugs have also been reported to possess CNS stimulation activity. ${ }^{5-8}$ Hence the present study was planned to study the effect of this formulation in the scopolamine- induced amnesia model in rats using Cook's pole apparatus. ${ }^{9}$

\section{METHODS}

\section{Study drugs}

\section{Brahmi ghrita (Test drug)}

The raw material including ghrita was procured from an authentic source. The plant material was first authenticated and the voucher specimen was preserved. Further, the standardization of the raw material was done as per "Quality Control Methods for medicinal plant materials", WHO, 1998 and Indian herbal pharmacopoeia. $^{10,11}$ After standardization of the raw material, bramhi ghrita was prepared in a local pharmacy under the supervision of the first author according to the methods described in Ayurvedic. ${ }^{12}$ The finished product was also standardized using the tests for fat and related substances such as rancidity, saponification value, refractive index etc.

\section{Piracetam (Positive control)}

Piracetam, a known nootropic agent, was used as a positive control and was procured from local market.

\section{Animals}

After obtaining Institutional Animal Ethics Committee permission, the study was carried out in 24 Wistar rats (68 weeks, 150-225 gms) of either sex. The animals were procured from national toxicology centre, Pune. The rats were housed in air-conditioned rooms $\left[23-30^{\circ} \mathrm{C}\right.$; humidity $(50-60 \%)]$, wherein the twelve hourly light and dark cycle was maintained. They were maintained on a standard pellet diet and purified water (by aquaguard) ad libitum.

\section{Training on cook's pole apparatus}

The animals were divided into 4 groups with 6 rats in each group. Animals from all groups were trained on the cook's pole apparatus, 30 sessions daily for 15 days, each session lasting 10 seconds. The Cook's pole apparatus is widely used to study the conditioned avoidance response in rats. This apparatus has a pole in the middle and the facility to apply current to the floor of the cage. The animal has to jump on the pole to avoid exposure to electric current. It was expected that they would achieve 95\%-99\% avoidance with this training.

\section{Study groups}

Group 1 animals were not given any treatment and served as the normal control. Group 2 animals served as the disease control. Group 3 animals were given the test drug, Brahmi ghrita orally, $450 \mathrm{mg} / \mathrm{kg}$ of b. w. (dose extrapolated from human dose of $5 \mathrm{gms} /$ day) daily for 15 days. Every day the training was done 1 hour after the drug administration. In the animals from group 4, after 15 days training like the other groups, a single dose of Piracetam (100 mg/kg, i. p., of body weight) was administered on $16^{\text {th }}$ day.

\section{Procedure to develop amnesia}

After 15 days of training, animals of group 2, 3 and 4 were given a single dose of scopolamine $(30 \mathrm{mg} / \mathrm{kg}$, i.p., of body weight) 60 minutes after the normal dosing time. Scopolamine, a muscarinic receptor antagonist, induces amnesia in various animal models. It has been reported to impair passive avoidance task, spatial memory deficits, and working memory impairment in radial arm maze and in the three-panel runway apparatus. ${ }^{13}$

\section{Assessment parameters}

Cook's pole avoidance test was carried out at 4 hours (half-life of scopolamine) and 24 hours (in order to test reversibility of the scopolamine effect) after administration of scopolamine. For this test, the animals were placed in the apparatus, and the buzzer was rung and 10 seconds later, the shock was applied to the animals. After completion of one session, the animals were placed back into their cage for 30 seconds and then placed back in the cook's apparatus again for the next session. Each animal was given a total of 30 sessions every day.

The response demonstrated by the animals was divided into three categories; when the animal showed no response even after being given the shock; it was termed as no response (NR), when the animal climbed onto the cage after being given the shock, the response was termed as unconditional response (UR) and when the animal climbed onto the pole, only after listening to the buzzer or as soon as it was kept in cage, the response was termed as conditional avoidance response (CAR).

After subjecting the animals to Cook's pole test at 24 hours, blood was collected from retro-orbital plexus for estimation of serum lipoperoxidase. The animals were then sacrificed and their brain dissected for the assessment of brain lipoperoxidase and acetylcholine esterase (AchE) activity. Both serum and brain lipoperoxidase activity was estimated in terms of MDA by the thiobarbituric acid (TBA) reaction. ${ }^{14}$ Estimation of brain acetylcholine esterase activity was also done by 
Ellman's method. ${ }^{15,16}$ The AchE activity was expressed in terms of protein content in the supernatant of rat brain homogenate, which was determined by the method of Lowry et al. ${ }^{17,18}$

\section{Statistical analysis}

Data was expressed as mean \pm S.D. Normal control animals were compared with the disease control animals. The drug treated animals (both Brahmi ghrita and Piracetam) were compared with the diseased animals. Parametric data involving more than 2 groups was analysed using one way ANOVA followed by Tukey's post-test, whereas comparison of 2 groups was done using student's unpaired 't' test . Non-parametric data was analysed using Chi square test. A value of $\mathrm{p}<0.05$ was considered to be statistically significant.

\section{RESULTS}

Brahmi ghrita showed a significant increase in CAR as compared to disease control and Piracetam treated animals (Table 1). The improvement in CAR was maintained in Brahmi ghrita treated animals even 24 hours after scopolamine administration. The increase in CAR at this time point was also statistically significant in comparison with disease control and Piracetam treated animals (Table 2).

Table 1: Effect of scopolamine after 4 hours of administration.

\begin{tabular}{|llll|}
\hline Groups & CAR & UR & NR \\
\hline $\begin{array}{l}\text { Normal } \\
\text { control }\end{array}$ & $29.8 \pm 0.44$ & $0.2 \pm 0.44$ & $0 \pm 0$ \\
\hline $\begin{array}{l}\text { Disease } \\
\text { control }\end{array}$ & $1.4 \pm 2.07^{\$ \$}$ & $11.2 \pm 2.77^{\$ \$ \$}$ & $17.4 \pm 2.88^{\$ \$ \$}$ \\
\hline $\begin{array}{l}\text { Bramhi } \\
\text { ghrita }\end{array}$ & $23 \pm 3.22^{* * * *}$ & $4 \pm 1.78^{* *}$ & $3 \pm 1.67^{* * *}$ \\
\hline Piracetam & $17.2 \pm 2.16^{* * * \# \#}$ & $8.6 \pm 3.78^{\#}$ & $3.4 \pm 1.67^{* * *}$ \\
\hline
\end{tabular}

$\$ \$ \$ p<0.001$ as compared to normal control using student's unpaired t test, $* * \mathrm{p}<0.01, * * * \mathrm{p}<0.001$ as compared to disease control, \#p<0.05, \#\# p<0.01 as compared to Bramhi ghrita using ANOVA followed by Tukey's test

Table 2: Effect of scopolamine after 24 hours of administration.

\begin{tabular}{|lll|l|}
\hline Groups & CAR & UR & NR \\
\hline $\begin{array}{l}\text { Normal } \\
\text { control }\end{array}$ & $29.2 \pm 0.44$ & $0.2 \pm 0.44$ & $0 \pm 0$ \\
\hline $\begin{array}{l}\text { Disease } \\
\text { control }\end{array}$ & $5.4 \pm 2.74^{\$ \$}$ & $8.4 \pm 1.90^{\$ \$}$ & $16 \pm 2.34^{\$ \$ \$}$ \\
\hline $\begin{array}{l}\text { Bramhi } \\
\text { ghrita }\end{array}$ & $26.83 \pm 1.83^{* * *}$ & $2.67 \pm 1.21^{* * *}$ & $0.5 \pm 0.83^{* * *}$ \\
\hline Piracetam & $22.8 \pm 1.78^{* * * \#}$ & $5.6 \pm 1.34^{* \#}$ & $1.6 \pm 1.51^{\text {*** }}$ \\
\hline
\end{tabular}

$\$ \$ \$ p<0.001$ as compared to normal control using Student's unpaired t test, $* \mathrm{p}<0.05, * * * \mathrm{p}<0.001$ as compared to disease control, $\# \mathrm{p}<0.05$ as compared to Bramhi ghrita using ANOVA followed by Tukey's test

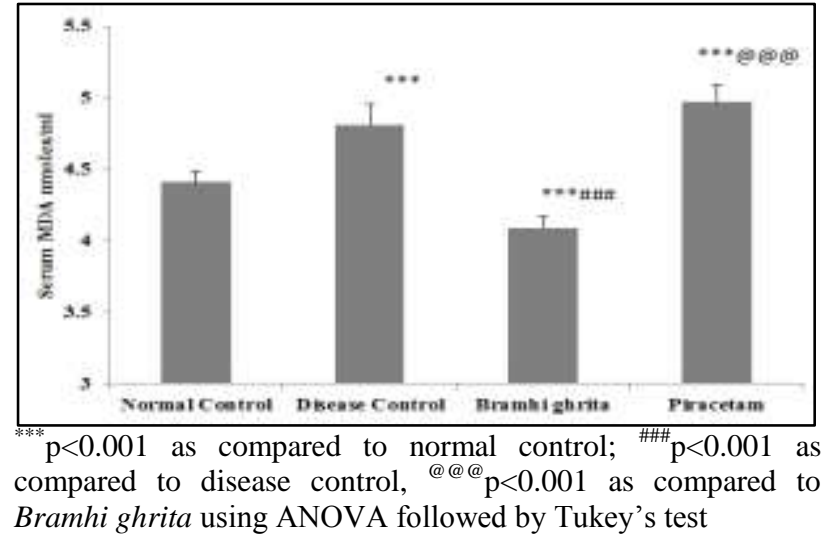

Figure 1: Effect on serum MDA.

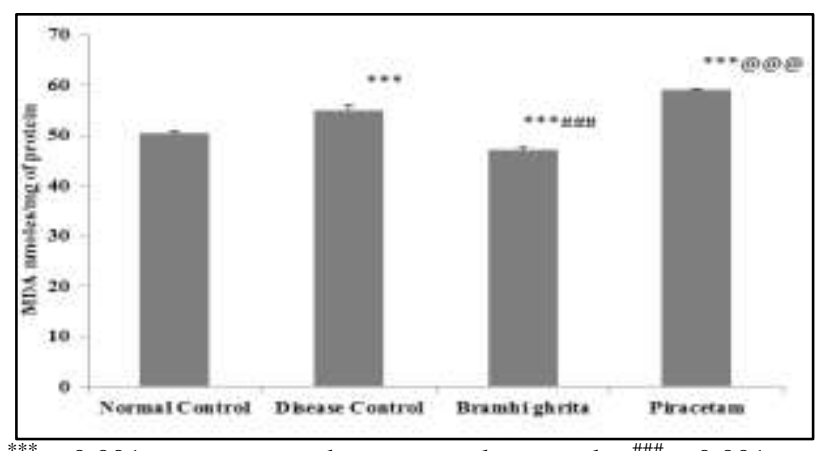

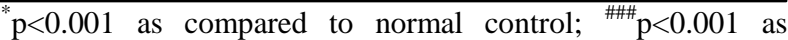
compared to disease control, ${ }^{@ @} \mathrm{p}<0.001$ as compared to Bramhi ghrita using ANOVA followed by Tukey's test

Figure 2: Effect on brain MDA.

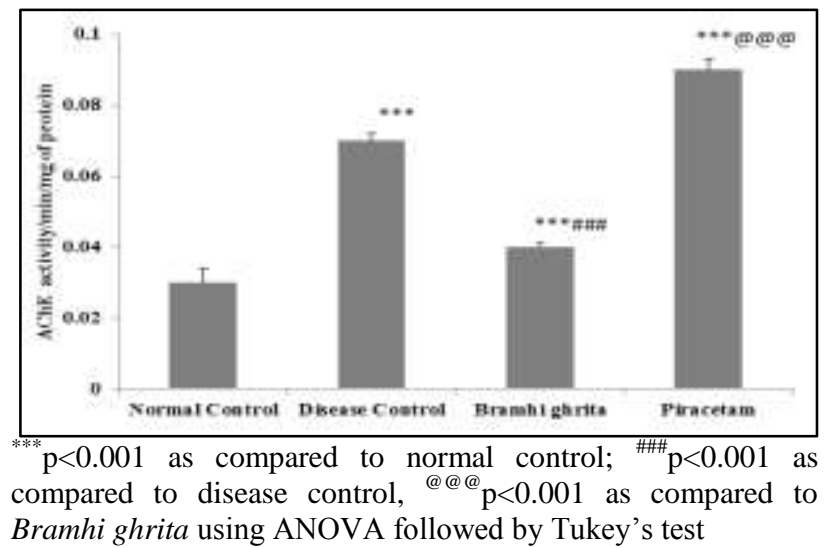

Figure 3: Effect on brain AChE activity.

In case of biochemical parameters, serum MDA level in Brahmi ghrita treated group was significantly less as compared to other 3 study groups, including normal control animals (Figure 1). Brahmi ghrita treated animals showed significant improvement in brain MDA as well in comparison with diseased and Piracetam treated animals (Figure 2). In case of both serum and brain MDA, Piracetam treated animals showed higher levels than the diseased animals. 
Brahmi ghrita treated animals exhibited significant reversal of the increased AchE activity induced by scopolamine. Like MDA, Piracetam treated animals increased the AChE activity also (Figure 3).

\section{DISCUSSION}

In the present study, we evaluated the effect of pretreatment of Brahmi ghrita in scopolamine induced amnesia in rats and compared it with Piracetam, a known nootropic drug. We observed that both drugs showed significant improvement in conditional avoidance response (CAR) indicating protective effect of these drugs against scopolamine induced damage of memory.

Along with behavioral parameters, we evaluated effect of bramhi ghrita on serum and brain lipid peroxidation (LPO) by measurement of its secondary product, malondialdehyde (MDA) and on acetyl cholinesterase (AChE) activity.

Bramhi ghrita significantly improved levels of both serum $(4.09 \pm 0.08)$ and brain MDA $(47.14 \pm 0.58)$ as compared to serum $(4.81 \pm 0.14)$ and brain $(55.07 \pm 1.00)$ MDA levels in the disease control group. Piracetam further augmented oxidative stress induced by scopolamine as revealed by increase in MDA levels in serum and brain. LPO is a free radical-related process that may or may not occur under enzymatic control. The nonenzymatic production of LPO is associated mostly with cellular damage as a result of oxidative stress. In this process MDA and 4-hydroxynonenal (HNE) are generated as secondary products. The increased generation of reactive oxygen species (ROS) is implicated in the pathogenesis of many diseases and in the toxicity of a wide range of compounds. Brain tissue is rich in polyunsaturated lipids, has high iron content, and is critically dependent on aerobic metabolism and thus highly vulnerable to ROS mediated oxidative damage. There are reports suggesting accumulation of LPO products in the brain of patients with Alzheimer's disease. $^{19,20}$

Brahmi ghrita showed a reduction of the AchE activity $(0.04 \pm 0.001)$ that had increased after administration of scopolamine $(0.07 \pm 0.002)$. Like MDA, Piracetam further increased the AChE activity $(0.09 \pm 0.003)$. It is reported that decrease in AChE activity can lead to improvement in learning and memory. ${ }^{21}$ Our results emphasize memory protective effect of Brahmi ghrita.

\section{CONCLUSIONS}

Overall, our study demonstrated protective effect of bramhi ghrita in the scopolamine induced amnesia model. It would be further interesting to study whether the effect is due to the plant component of the formulation, its ghrita part or the synergistic effect of the two, as every plant in the formulation is known to have intellect promoting activity and the ghrita used as a vehicle in the formulation has similar properties.

\section{ACKNOWLEDGEMENTS}

The authors are thankful to Mr. Kanak Gawde for his technical assistance.

Funding: Research Society, TN Medical College \& BYL Nair Ch. Hospital

Conflict of interest: None declared

Ethical approval: The study was approved by the Institutional Animal Ethics Committee

\section{REFERENCES}

1. Simple definition of memory. Available at http://www.merriam-webster.com/dictionary/memory Accessed 28 January 2016.

2. Joshi H, Parle M. Evaluation of nootropic potential of ocimum sanctum Linn. In mice. Indian J Exp Biol. 2006;44:133-6.

3. Achliya GS, Wadodkar SG, Dorle AK, Evaluation of CNS activity of bramhi ghrita. Indian J Pharmacol. 2005;37(1):33-6.

4. Vd. Jadavji Trikamji Acharya, $10^{\text {th }}$ chapter. In Chikitsa Sthan, Charaka Samhita. $5^{\text {th }}$ ed. Varanasi: Chaukhambha Surbharti Prakashan; 2001:475-476.

5. Vinutha B, Prashantha D, Salma K. Screening of selected Indian medicinal plants for acetyl cholinesterase activity. J Ethnopharmac. 2007;109(2):359-63.

6. Chittaranjan A, Chandra SJ. Anti-amnestic property of brahmi and mandookparni in a rat model. Indian $\mathbf{J}$ Phychiatry. 2006;48:232-7.

7. Chopra RN, Nayar SL, Chopra IC. Glossary of Indian medicinal plants. Council of Scientific and Industry Research, New Delhi; 1956:32:74.

8. Uphof JC. The dictionary of economic plants. Verlag von J Cramer, NewYork; 1968:62:94.

9. Sreemantula S, Nammi S, Kolanukonda R, Koppula S, Boini KM. Adaptogenic and nootropic activities of aqueous extract of vitis vinifera (grape seed): an experimental study in rat model. BMC Complementary and alternative medicine. 2005;5(1):1472-80.

10. Indian herbal pharmacopoeia. Regional research laboratory, Jammu-Tawi and Indian drug manufacturer's association, Mumbai; 2002.

11. Quality control methods for medicinal plant materials. World health organization, Geneva; 1998.

12. Ambikadattashastri, editor. Baishjyaratnavali. Apasmarchikitsa. $14^{\text {th }}$ ed. Published by Chaukhabha Sanskrit Sansthana; 2001:372.

13. Naveen K, Kohli K. Effect of metoclopramide on scopolamine-induced working memory impairment in rats; Indian J Pharmacol. 2003;35:104-8.

14. Buege JA, Aust SD. Microsomal lipid peroxidation. Methods in Enzymology. 1978;52:302-10. 
15. Ellman GL, Courtney KD, Andres V, Stone RM. A new and rapid colorimetric determination of acetyl cholinesterase activity. Biochem Pharmacol. 1961;7:88-95.

16. Srikumar BN, Ramkumar K, Raju TR, Rao BS. Assay of acetylcholiesterase activity in the brain. Brain and Behavior. 2004:142-4.

17. Lowry OH, Rosebrough NJ, Farr AL, Randall RJ. J. Biol Chem. 1951;193:265.

18. Wilson K, Walker J. Practical biochemistry: principles and techniques. Cambridge University Press; 2000.

19. Bayani U, Singh AV, Zamboni P, Mahajan RT. Oxidative stress and neurodegenerative diseases: a review of upstream and downstream antioxidant therapeutic options. Current Neuropharmacology. 2009;7:65-74.

20. Romero FJ, Morell FB, Romero MJ, Jareflo EJ, Romero B, Marin N, et al. Lipid peroxidation products and antioxidants in human disease. Environmental Health Perspectives. 1998;106(5):1229-34.

21. Sudha S, Lakshmana MK, Pradhan N. Changes in learning and memory, acetylcholinesterase activity and monoamines in brain after chronic carbamazepine administration in rats. Epilepsia. 1995;36(4):416-22.

Cite this article as: Munshi R, Bhalerao S, Nesari T. Evaluation of the efficacy of Brahmi ghrita in scopolamine induced amnesia in rats using Cook's pole apparatus. Int $\mathrm{J}$ Basic Clin Pharmacol 2016;5:829-33. 